\title{
OS CÓDIGOS DE ÉTICA EMPRESARIAIS SOB A PERSPECTIVA DE COERÊNCIA E COESÃO: UM ESTUDO À LUZ DA LEI SARBANES- OXLEY
}

\author{
Emiliano Carlos Serpa Castor \\ Universidade Santa Úrsula \\ emiliano.castor@gmail.com \\ Ana Carolina de Gouvêa Dantas Motta \\ Universidade Santa Úrsula \\ anacarolinadegouvea@gmail.com \\ Adriano Rosa da Silva \\ Universidade Santa Úrsula \\ 66.rosa@gmail.com \\ Juliano Melquiades VianelloAutor \\ Universidade Santa Úrsula \\ juliano.vianello@usu.edu.br
}

\begin{abstract}
Resumo
Valor ou premissa de uma organização, a ética empresarial vem para assegurar tanto a sobrevivência como a reputação de uma empresa, seja ela pública ou privada. E, como é de se supor, os seus bons resultados. Por meio desta perspectiva, busca-se, neste artigo, estudar os códigos de ética sob o ponto de vista de coerência e de coesão, à luz do termo accountability, tendo como referência de partida a Lei Sarbanes-Oxley (SOX). Assim, a forma moralmente correta com que as empresas interagem com o seu meio envolvente revela-se o fio condutor deste trabalho, particularizado nas cinco empresas brasileiras com os melhores desempenhos na Bolsa de Valores de Nova Iorque (NYSE), no recorte temporal entre janeiro e julho de 2016.
\end{abstract}

Palavras-chave: Ética. Ética Empresarial. Governança Corporativa. Código de Ética. Lei Sarbanes-Oxley (SOX).

\section{THE CODES OF BUSINESS ETHICS UNDER THE PERSPECTIVE OF COHERENCE AND COHESION: A STUDY FROM THE SARBANES-OXLEY LAW}

\begin{abstract}
Value or premise of an organization, business ethics aims to ensure both the survival and the reputation of a company, whether public or private, while pursuing good results. This article seeks to study the codes of ethics under the point of view of coherence and cohesion, under the term accountability, starting with the Sarbanes-Oxley (SOX). Thus, the morally correct way companies interact with their environment is the main driver of this work, one of the five Brazilian companies with the best performance on the New York Stock Exchange (NYSE), from January to July 2016
\end{abstract}

Keywords: Ethics. Business Ethics. Corporate Governance. Code of Ethics. Sarbanes-Oxley Act (SOX). 


\section{INTRODUÇÃO}

Os mais recentes fatos do cenário político-econômico brasileiro, tal como a Operação Lava Jato (deflagrada em 2014 e com significativos desdobramentos no processo de rearranjo político até os dias atuais do presente artigo), deram expressiva visibilidade e amplificaram ainda mais a discussão em torno de um tema que jamais caiu em desuso: a ética (sobretudo na esfera das relações laborais e político-econômicas). Concretamente no âmbito empresarial, foco deste trabalho, tal panorama acabou por colocar em evidência muitos dos conceitos éticos até então defendidos e aplicados no cenário de governança corporativa, mais precisamente o de accountability - para além dos de compliance, disclosure e fairness.

Muito embora o termo accountability ainda seja recente no contexto brasileiro, a sua aplicabilidade e essência sempre fizeram aqui todo o sentido, já que representa uma forma de proteger, de salvaguardar os cidadãos de má conduta burocrática. Uma das primeiras referências a respeito, no contexto brasileiro, partiu de Ana Maria Campos (1990) ${ }^{\mathrm{i}}$, que entende e relaciona o termo accountability à responsabilidade objetiva - e não subjetiva - ou como obrigação de responder por algo.

De fato, o termo ganha indiscutível importância quando se aborda, tal como nos dias atuais, o desenvolvimento e a manutenção de estruturas burocráticas que tanto impeçam como também punam as práticas de abusos éticos no sentido de proteger o Estado e os cidadãos contribuintes. Como a própria autora explica (Campos, 1990, p. 33):

\footnotetext{
[...] a inevitável necessidade do desenvolvimento de estruturas burocráticas para atendimento das responsabilidades do Estado traz consigo a necessidade da proteção dos direitos dos cidadãos contra usos (e abusos) do poder pelo governo como um todo, ou de qualquer indivíduo investido em função pública.
}

Neste contexto, Samuel Paul (1992), entende accountability como uma junção de previsões e de ações corretivas e punitivas que se dão a partir do acompanhamento da gestão pública, a qual se refere como um "conjunto de abordagens, mecanismos e práticas usados pelos atores interessados em garantir um nível e um tipo desejados de desempenho dos serviços públicos" (PAUL, 1992, p. 1047).

Já Ricardo Ceneviva (2006), entende a ideia de accountability como uma ampliação de responsividade (answerability) no sentido de os líderes empresariais ou governamentais, havendo a capacidade de agentes fiscalizadores, demandarem aos líderes as justificativas por seus atos e/ou omissões e, eventualmente, lhes atribuírem algum tipo de sanção.

Todavia, nem todos os países encontram-se nesta posição privilegiada de gestão ética. Campos (1990), discorre sobre o fato de que a falta de "amadurecimento democrático" em 
países tidos como econômica e politicamente menos desenvolvidos abrem terreno fértil para diversos precedentes, sobretudo jurídicos, e para a aceitação passiva, por parte do Estado, de ações de abuso de poder, bem como o uso, pelos próprios governantes, da máquina estatal em benefício próprio.

No caso do Brasil, por exemplo, José Antonio Pinho e Ana Rita Sacramento (2009), contextualizam que, de fato, houve uma expressiva evolução na conscientização social no que tange à intervenção democrático-participativa na observância e no controle político do governo nos últimos 20 anos. E foi justamente a história que deu ferramentas para esta mudança de paradigmas: a promulgação de uma nova Constituição e a abertura de um processo democrático ${ }^{\text {ii. }}$ Somam-se a esse novo cenário no Brasil sucessivas reformas do aparelho do Estado (sobretudo a partir de 1995), no sentido de tornar a administração pública mais eficiente e controlável. Desta forma, Pinho e Sacramento (2009), julgam que tais mudanças representam uma aproximação do conteúdo do conceito de accountability à uma realidade mais ética da administração pública brasileira ${ }^{\text {iii }}$.

Ainda sobre o termo accountability, é pertinente mencionar dois aspectos importantes no que tange às suas “dimensões”, entendidas como vertical e horizontal. Guillermo O’ Donnel (1998), propõe que a primeira seja analisada na dimensão legal e política com viés de responsabilidade ou dever de prestação de contas dos atos (Pontes, 2008), estabelecendo então foco em eleições, premiação e punição. Já para a dimensão horizontal da accountability, O' Donnel (1998), sugere uma relação de equilíbrio de poder, a qual, segundo o autor, vem a partir da noção de "check and balances", permitindo, assim, mútua vigilância entre os três poderes do Estado - sendo todos eles autônomos (Pontes, 2008). Tal relação, como o próprio autor define e complementa, representa o "velho tema da divisão dos poderes e dos controles e equilíbrios entre eles".

Neste contexto e a partir dos conceitos de accountability vertical e horizontal, define-se a accountability societal, que representa, na verdade, uma forma de ampliação significativa do conceito da vertical, uma vez que se caracteriza, nomeadamente, como uma "forma de atuação da sociedade no controle das autoridades políticas, com ações de associações de cidadãos e de movimentos, com o objetivo de expor os erros governamentais e ativar o funcionamento das agências horizontais" (PONTES, 2008, p. 39).

Desta forma, para que a prática de accountability ocorra eficazmente, torna-se importante que haja a comunhão das dimensões vertical, horizontal e societal, aliadas aos mais diversos controles formais e informais, de fácil entendimento e de acompanhamento da 
sociedade civil, visando, assim, ter administrações objetivamente responsáveis e transparentes (PONTES, 2008).

Neste contexto, o entendimento ainda mais crítico e aprofundado tanto do significado como da função social das práticas éticas e, como é de se supor, do termo de accountability, tem ganho visibilidade e discussão cada vez maiores nos meios de comunicação social brasileiros o que implica, por sua vez, um maior interesse por parte dos cidadãos - algo então conjeturado por Pinho e Sacramento (2009).

Contribui igualmente para esse fato o (des)alinhamento entre como as empresas se propõem a se portar e a se relacionar com o mundo por meio de seus códigos de éticas e o que, sob a luz de práticas inibitórias de corrupção, o mundo exterior exige delas. Faz-se então importante identificar se os discursos dos códigos de ética apresentam-se e aplicam-se de forma generalista ou, justamente o oposto, mostram-se devidamente claros, específicos e direcionados. Sejam eles quais forem, é de importância basilar que tais códigos sejam coerentes com pelo menos os pontos fundamentais de leis que fomentam atividades transparentes, tal como a Lei Sarbanes-Oxley (2002).

Lei norte-americana criada em 2002 pelo senador democrata Paul Sarbanes e pelo deputado republicano Michael Oxley, a lei acima referida veio para evitar fraudes em investimentos financeiros e, assim, criar transparência processual no que se diz respeito à governança adequada por parte das empresas (GITMAN, 2010).

No Brasil, a existência e a divulgação de um código de ética nas organizações desta natureza são recomendadas pelo Código do IBGC (Instituto Brasileiro de Governança Corporativa) e exigidas pela seção 406 da Lei Sarbanes-Oxley (SOUZA et al., 2011). Ainda neste contexto, como afirmam Raiziane Silva e Rosane Seibert (2015), a lei está intimamente ligada às práticas de compliance, accountability, disclosure e fairness e colaboram para uma postura ética e legal das empresas ${ }^{\mathrm{iv}}$.

Desta forma, este trabalho entende que os itens que compõem cada seção fundamental da Lei Sarbanes-Oxley (2002), representam uma unidade coesa. Ou seja, para cada seção fundamental, de forma análoga ao que foi mencionado no parágrafo anterior, há um conjunto de itens que podem ter ou não ligações provenientes dos códigos de ética, o que estabelece o quão coeso está o código a cada seção fundamental da lei. Tal resultado permite perceber e identificar, qualitativamente, se há ou não a presença de coesão e se essa se dá ou não por mera formalidade.

Partindo-se então do pressuposto de que cada empresa conta com o seu código de ética - e estabelecer uma generalização nesse sentido é pouco provável -, optou-se então por 
estabelecer uma relação das empresas brasileiras com bom desempenho na Bolsa de Valores de Nova Iorque (NYSE) a fim de se compreender se há ou não a existência de coerência e de coesão tal como fora problematizado e proposto nos parágrafos anteriores. Por este caminho, o presente artigo busca encontrar relações qualitativas entre o que é proposto pelas cinco grandes empresas brasileiras com melhor desempenho na NYSE (entre janeiro e julho de 2016), por meio de seus respectivos códigos de ética, e os alicerces da Lei Sarbanes-Oxley (2002), agrupados pelas seções 302, 401, 404 e 409 (SOXLAW, 2017). Desta forma, buscar-se-á compreender a coerência e a coesão do discurso de ética e as práticas exigidas pela lei nas referidas seções, bem como se esses discursos se dão apenas por mera formalidade de compliance.

\section{2 ÉTICA}

As reflexões éticas são, desde sempre, algumas das grandes preocupações do ser humano. No entanto, a percepção ética de Sócrates ${ }^{\mathrm{v}}$ passou por incontáveis reflexões, das mais heterogêneas possíveis, sobretudo nos âmbitos religiosos - mas também nos laicos (KAIZELER; FAUSTINO, 2008).

Ainda que existam inúmeras interpretações a respeito desta questão, Marlene Graham (2009), nos relembra um aspecto basilar e transversal da ética: a forma como devemos agir nos relacionamentos e, assim, como devemos viver uns com os outros. Tal ponto, ainda segundo a autora, abre então possibilidades para um confronto diário na vida dos seres humanos dotados de racionalidade crítica: se as nossas ações são, de fato, condizentes com o nosso contexto vivido. Assim, Graham nos desafia levantando questões sobre como os valores, as regras e os traços de caráter que ajudam o homem a se desenvolver (tais como a integridade, a honestidade, a fidelidade e a compaixão) se desenrolam efetivamente na vida cotidiana.

Já para Manfredo Oliveira (1993), a ética está ligada à consciência do que o homem deve ser, e que isso está vinculado ao fato de, diferentemente de outros animais primatas, enquanto sapiens sapiens, diferenciar-se por ser essencialmente racional e consciente das suas ações. Assim, não tendo um comportamento completamente pré-determinado, entende-se que o ser humano possui alguma autonomia nas suas decisões e ações. A partir desta perspectiva, diferentes contextos e diferentes costumes vão moldando diferentes comportamentos e, assim, diferentes problemáticas éticas. No entanto, ainda que problemáticas éticas bem heterogêneas existam, todas hão de convergir para as práticas ditas generalizadas, como entendeu Graham (2009). 
Num mundo cada vez mais globalizado, para que as relações entre comunidades de diferentes culturas possam ocorrer, formas cada vez mais padronizadas de se conduzir situações se fizeram necessárias. Por esse caminho, Ana Catarina Kaizeler e Horácio Faustino (2008), refletem sobre a possibilidade de existência de uma ética universal no atual contexto. Os autores difundem a ética da globalização como parte da seguinte realidade: a de existência de uma só atmosfera, uma só economia e uma só comunidade - apesar de se reconhecer como desafios a tolerância e o respeito inter-religiosa/o e o entre classes sociais na sociedade contemporânea.

Já no contexto corporativo, a globalização toma uma face ainda mais estandardizada dado o posicionamento consolidado dos Estados Unidos, de alguns países da Europa Ocidental e da China na condução de práticas tidas como monopódicas e assimétricas e destoantes em termos éticos. Tal como os Estados Unidos, que detêm protagonismo no cenário corporativo na maioria dos setores da economia ${ }^{\mathrm{vi}}$ e, desta forma, determina as regras do (seu) jogo no universo corporativo. Vale destacar

Há diversos exemplos do protagonismo norte-americano neste sentido (alguns deles presentes neste relatório de pesquisa), dos quais podemos citar a The New York Stock Exchange (NYSE), bolsa de valores situada na região de Wall Street, em Nova Iorque. Este cenário de unilateralidade nas decisões econômicas resulta num significativo ambiente de pressão por resultados, onde, por muitas vezes, "os fins justificaram os meios"vii.

Com os sucessivos escândalos corporativos nos Estados Unidos na década de 90 e início dos anos 2000, novas leis foram promulgadas naquele país a fim de se solidificar o controle de empresas de capital aberto, inclusive com a imposição e a criação de códigos de ética. Parte destas ações mais incisivas resultou de uma expressiva reação da sociedade por posicionamentos socialmente mais éticos e adequados das empresas, por meio da consolidação da prática cidadã, criando-se mecanismos de cobrança ou de responsabilização de agentes em ação estatal e privada.

Desta forma, a ética empresarial tem buscado impedir que as organizações assumam posicionamentos de lucro a todo custo e, assim, acarrete em graves problemas sociais. Ou seja: por meio de princípios rigorosamente determinados, a ética empresarial vem desestimulando as empresas do impulso de executar atividades prejudiciais, e até mesmo criminosas, à coletividade (REGINATTO, 2012).

Paralelamente, Joaquim Moreira (1999), entende a ética empresarial como um valor da empresa que assegura a sua sobrevivência, a sua reputação e, desta forma, os seus bons resultados. Assim, a ética empresarial representa o comportamento da entidade lucrativa em conformidade com os princípios morais e as regras éticas aceitas pela coletividade ${ }^{\text {viii }}$. 
Como anteriormente aqui descrito, no Brasil, o entendimento acerca da ética empresarial chegou de forma tardia relativamente aos Estados Unidos. O tema passou a ser tratado somente em 1995, pelo IBGC (Instituto Brasileiro de Governança Corporativa), por meio do Código das Melhores Práticas de Governança Corporativa ${ }^{1}$. Fundado em 1995, o instituto, de cariz associativo em âmbito nacional e sem fins lucrativos, dedica-se exclusivamente à promoção da governança corporativa no Brasil (IBGC, 2015). Já o Código das Melhores Práticas de Governança Corporativa, hoje um marco de governança corporativa, tem como finalidade contribuir para o desempenho sustentável das organizações e influenciar os agentes de nossa sociedade a pautarem-se nos princípios éticos, no sentido de maior transparência, justiça e responsabilidade.

Retomando então os aspectos de ética empresarial, para que tais princípios sejam colocados em prática, torna-se fundamental a existência e a divulgação de um código de ética nas organizações são mandatárias. Para este fim, a Lei Sarbanes-Oxley -recomendada pelo Código dos IBGC (2015) - amplamente aqui referida, cumpre adequadamente tais requisitos no Brasil.

THE US SARBANES-OXLEY ACT (2017), explica que a seção 406 da Lei SOX pode ser dividida em quatro partes, a saber: code of ethics disclosure; changes in codes of ethics; definition; deadline for rulemaking, ou seja, divulgação, evidenciação e publicação do código de ética, revisões nos códigos de ética, definições e prazos para revisão de regulamentações.

No tocante à divulgação, evidenciação e publicação do código de ética, a Lei SOX exige que os códigos de conduta e de ética estejam claros, disponíveis aos envolvidos e que não deixem de esclarecer o comportamento e as ações esperadas aos altos executivos financeiros, como, por exemplo, diretor financeiro, controlador, contador principal e/ou profissionais que desempenham funções semelhantes.

Em relação à revisão, são requeridas revisitações periódicas ao documento de código de ética a fim de revalidar a sua aplicabilidade e promover atualizações necessárias. Além disso, são estipulados prazos para que as definições realizadas sejam regulamentadas e postas em prática.

Finalmente, em relação às definições, a seção 406 da Lei SOX estabelece três pilares, a saber: 1) incluir a conduta ética em relação a conflitos de interesses reais ou aparentes e relações profissionais; 2) deixar claro nos relatórios que o emitente deve apresentar, de forma completa, justa, rotineira e rápida (quando não rotineira) e, por fim, 3) deixar claro a conformidade com as regras governamentais aplicáveis. 
No Brasil, o código do IBGC de 2015, analisa o código de ética sob duas óticas: o seu fundamento e as suas práticas. Assim, tal órgão fundamenta o código de ética como o principal promotor de princípios éticos. E não só: torna-se demandante de reflexão em relação à identidade e à cultura organizacionais, escorado em responsabilidade, respeito, ética e considerações de ordem social e ambiental. O IBGC ainda deixa claro que a criação e o cumprimento de um código de ética elevam o nível de confiança interno e externo na empresa, tendo então como consequência a valorização da reputação e da imagem empresarial - o que de fato contribui para a sensação de confiabilidade e de transparência da companhia.

Quanto às práticas, o código do IBGC (2015) ${ }^{\text {ix }}$, estabelece a necessidade de se transcorrer no sentido de "fomentar a transparência disciplinar, as relações internas e externas da organização, administrar conflitos de interesses, proteger o patrimônio físico e intelectual e consolidar as boas práticas de governança corporativa”. Realça também a abrangência do código onde "cada organização deve contar com seu próprio código de conduta, que deve refletir sua identidade e cultura", deixando claro o que deve estar contido, mas o como fica a cargo de cada empresa.

Finalmente, o código do IBGC recomenda a criação de um canal de denúncias que visa garantir o anonimato e ter formas sólidas de acolher opiniões, críticas, reclamações e/ou denúncias, o que contribui para antecipar-se, proibir e/ou evitar a ocorrência de fraudes e corrupção.

\section{1 ÉTICA E GOVERNANÇA CORPORATIVA}

A partir então deste novo contexto de desvio de ética observado atualmente, tanto na esfera pública como na privada, diversos foram os artifícios de regulação criados para se evitar fraudes e corrupção, sobretudo nos países economicamente mais expressivos. Um deles merece destaque: a Committee of Sponsoring Organization of the Treadway Commission (COSO) ${ }^{\mathrm{x}}$, nos Estados Unidos, que desenvolveu recomendações vitais sobre governança corporativa direcionadas às empresas públicas americanas e aos seus auditores independentes, tais como a Securities and Exchange Commission (SEC) e outros reguladores nos Estados Unidos. Por meio desta ação interventiva, ao longo dos anos, a COSO tem se posicionado na formação de liderança de pensamento no tocante a três assuntos inter-relacionados: gerenciamento de risco empresarial, controle interno e dissuasão de fraude ${ }^{\mathrm{xi}}$.

Não menos importante está o órgão, também norte-americano, Securities and Exchange Commission (SEC), que normatiza as empresas que emitem American Depositary Receipts 
(ADRs), ou seja, aquelas que representam os recibos de ações na bolsa de valores de Nova Iorque, logo, normatizando a NYSE. Relativamente aos sistemas de controle internos, uma das exigências da SEC é a recomendação, junto às empresas com negócios na NYSE, da utilização do framework criado pela COSO (relatório criado em 2001), a Enterprise Risk Management (ERM) - Integrated Framework, ou seja, o Gerenciamento de Riscos Corporativos (GRC) Estrutura Integrada. (SOUZA et al., 2011) ${ }^{\mathrm{xii}}$.

O relatório de Gerenciamento de Riscos Corporativos (estrutura integrada da COSO) é conhecido por COSO II ou COSO ERM. O relatório COSO I, criado em 1992, também abarcava práticas de controles internos, e a sua evolução resultou na publicação do COSO II, cerca de uma década mais tarde (SOUZA et al., 2011).

O COSO I teve como grande contribuição iniciar discussões de controle interno, com definições e racionalizações dos conceitos. Neste contexto, destaca-se a definição de controle interno como sendo (COSO,1992 apud FARIAS et al., 2009, p. 62):

[...] um processo, estabelecido pelo Conselho de Administração, Diretoria, Gerência ou outras pessoas da companhia, desenhado para prover razoável segurança de que os seguintes objetivos sejam atingidos: 1. Eficácia e eficiência das operações; 2. Confiabilidade dos relatórios financeiros; 3. Conformidade com as leis e normas aplicáveis.

De acordo com a COSO (2013), o framework ERM foi complementado com a ampliação da categoria de divulgação financeira no intuito de incluir outros formatos significativos de divulgação, como os internos e os não financeiros. Além disso, inclui considerações sobre as (muitas) mudanças nos ambientes operacionais e corporativos durante as últimas décadas, dentre elas (COSO, 2013): a) expectativas em relação à supervisão da governança; b) globalização dos mercados e das operações; c) mudanças nos negócios e maior complexidade; d) demandas e complexidades nas leis, regras, regulamentações e normas; e) expectativas em relação a competências e responsabilidades pela prestação de contas; f) uso de tecnologias em transformação e confiança nas mesmas; g) expectativas em relação à prevenção e à detecção de fraudes.

Assim, a COSO (2013, p. 6), definiu e reafirmou o controle interno como um processo “conduzido pela estrutura de governança, administração e outros profissionais da entidade, e desenvolvido para proporcionar segurança razoável com respeito à realização dos objetivos relacionados a operações, divulgação e conformidade".

Desta forma, na visão de processo de controle interno, a COSO entendeu e segmentou o controle interno em cinco componentes em relação ao gerenciamento de riscos, que são: 1) 
ambiente de controle; 2) avaliação de riscos; 3) atividades de controle; 4) atividades de informação e de comunicação e 5) atividades de monitoramento.

O primeiro deles, o componente de ambiente de controle, abarca a integridade e os valores éticos da organização. Ou seja, trabalham-se os parâmetros que permitem à estrutura de governança cumprir com as suas responsabilidades de supervisionar a governança, bem como a estrutura organizacional e a delegação de autoridade e responsabilidade (o processo de atrair, desenvolver e reter talentos competentes; bem como o rigor em torno de medidas, incentivos e recompensas por performance também fazem parte deste componente). Assim, o ambiente de controle resultante tem impacto abrangente sobre todo o sistema de controle interno (COSO, 2013).

Já o componente de avaliação de riscos, envolve um processo dinâmico e interativo para identificar e avaliar os riscos à realização dos objetivos. Assim, a administração especifica os objetivos dentro das seguintes agrupações: operacional, divulgação e conformidade. A administração também trata dos riscos quanto à adequação dos objetivos à entidade. Desta maneira, complementando o componente de avaliação de riscos, importa referir que ainda é preciso que a administração leve em consideração o impacto de possíveis alterações no ambiente externo e dentro do próprio modelo de negócios (COSO, 2013).

O componente de atividades de controle são ações idealizadas e colocadas em prática por meio de políticas e de procedimentos com a finalidade de assegurar o cumprimento de diretrizes determinadas pela administração, visando sempre mitigar os riscos à realização dos objetivos. Podem ser de natureza preventiva ou reativa e abrangem uma série de atividades manuais e/ou automáticas. São exemplos de atividades de controle: fluxos de autorizações e aprovações, verificações, reconciliações, revisões de desempenho do negócio e segregação de funções (COSO, 2013).

O componente de informação e de comunicação é o processo contínuo e interativo em que se proporciona, compartilha e obtém as informações necessárias, podendo ser constituído de duas formas: interna e externa. A primeira refere-se à corporação, e a segunda prevê o recebimento de informações, por parte organização, com posterior retorno a requisitos e expectativas (COSO, 2013).

O componente de atividades de monitoramento são ações contínuas, independentes ou uma mescla das duas, e tem a finalidade de garantir a existência e o correto funcionamento dos cinco componentes do controle interno, anteriormente aqui mencionados. Os resultados são avaliados em relação a critérios previamente acordados, sendo as possíveis deficiências 
comunicadas à estrutura de governança e de administração para que sejam tomadas providências de adequação (COSO, 2013).

$\mathrm{O}$ atual contexto político-econômico brasileiro fez com que o IBGC se posicionasse em termos de regulamentação. O instituto entende que é cada vez mais evidente a responsabilidade dos agentes de governança quanto aos assuntos referentes à sustentabilidade, corrupção, fraude, abusos nos incentivos de curto prazo para executivos e investidores - sem deixar de lado, como é suposto, a complexidade e a multiplicidade de relacionamentos que as organizações acordam com os mais diferentes públicos no Brasil (IBGC, 2015). Assim, visando definir e recomendar boas práticas, o IBGC fundamentou e explicitou o que entende como "boas práticas" de governança nos negócios na ótica da ética corporativa, a saber: transparência, equidade, prestação de contas e responsabilidade corporativa. Revisitando então os princípios do código, temos, respectivamente, em relação aos conceitos aqui mencionados anteriormente: disclosure, fairness, accountability e compliance.

Importa ainda mencionar, tal como destacam Souza et al. (2011), que o código do IBGC recomenda, dentre outras práticas de governança corporativa, as seguintes: a constituição de um comitê de auditoria, a existência de um código de conduta (ética), divulgado a todos os envolvidos; o gerenciamento de riscos corporativos; ouvidoria e canal de denúncias e controles internos. Essas recomendações vêm desde a quarta edição do código, em 2009.

\section{PROCEDIMENTOS METODOLÓGICOS}

Tendo então exposto e debatido questões de fulcral importância no que diz respeito às boas práticas de governança, importa brevemente descrever como se deu o trabalho metodológico no desenvolvimento deste artigo. O propósito fundamental que norteou este objeto de pesquisa desenvolveu-se a partir da descrição do grau qualitativo que representa a aderência de práticas centrais da Lei Sarbanes-Oxley (SOX) às práticas de conduta relatadas nos códigos de ética das empresas selecionadas para a pesquisa em questão. Para tanto, seguiuse o seguinte critério: a averiguação e posterior definição do melhor desempenho no mercado acionário da NYSE, no ano de 2016. Importa referir que o critério de desempenho em questão baseou-se nos requisitos da American Depositary Receipt, que representam os recibos de ações do mercado mencionado. A classe ADR verificada foi composta pelo desempenho ordinário da ação ao longo do primeiro semestre de julho de $2016^{\text {xiii }}$, recorte temporal delimitado para não comprometer o andamento da presente pesquisa. 
Partindo-se do entendimento de que todo método apresenta possibilidades, mas, por outro lado, limitações, como já afirmara Sylvia Vergara (2013), torna-se importante mencionar algumas dessas, as quais são referentes ao método escolhido para o presente estudo. A primeira diz respeito à limitação da abrangência da pesquisa às cinco empresas brasileiras com maior operação e venda de ação no mercado acionário de Nova Iorque, no ano de 2016, uma vez que deixa à parte outras empresas importantes do cenário nacional que, em função do recorte temporal aqui definido e dos recursos disponíveis, não seria possível ter uma amostra maior.

Outros aspectos a considerar são o viés e a interpretação do pesquisador no tratamento dos dados e na geração dos resultados obtidos. A postura do pesquisador foi a de que a pesquisa tivesse o distanciamento necessário, ainda que se admita a inexistência de neutralidade investigativa.

\section{DISCUSSÃO, ANÁLISE DE DADOS E RESULTADOS}

Tendo então brevemente descrito algumas das principais linhas metodológicas, partirse-á para a descrição das empresas. O Quadro 1 mostra um recorte com a relação das cinco empresas brasileiras com melhor desempenho de janeiro a julho de 2016.

Quadro 1: Recorte com as cinco empresas brasileiras com melhor desempenho de janeiro a julho de 2016.

\begin{tabular}{|r|c|c|c|}
\hline \multirow{2}{*}{ Posição } & Compa nhia & $\begin{array}{c}\text { Crescimento } \\
\text { Ordinário } \\
\text { (até 14/07) }\end{array}$ & $\begin{array}{c}\text { Preço do Papel } \\
\text { (US\$ em 14/07) }\end{array}$ \\
\hline 1 & CSN & $207,14 \%$ & 3,01 \\
\hline 2 & GOL & $139,82 \%$ & 13,67 \\
\hline 3 & SABESP & $103,23 \%$ & 9,26 \\
\hline 4 & Bradesco & $99,99 \%$ & 8,63 \\
\hline 5 & CEMIG & $91,52 \%$ & 2,65 \\
\hline
\end{tabular}

Fonte: O autor, 2019.

Neste contexto de pesquisa, buscou-se descrever qualitativamente quatro seções fundamentais da Lei SOX (seções 302, 401, 404 e 409) nos códigos de ética das empresas selecionadas a fim de se compreender a mensagem de transparência empresarial desde o documento público das companhias. Sumário de seção SOX disposto no quadro 2: 
Quadro 2: Textos resumidos das seções 302, 401, 404 e 409 da Lei SOX. (Traduzido pelo autor).

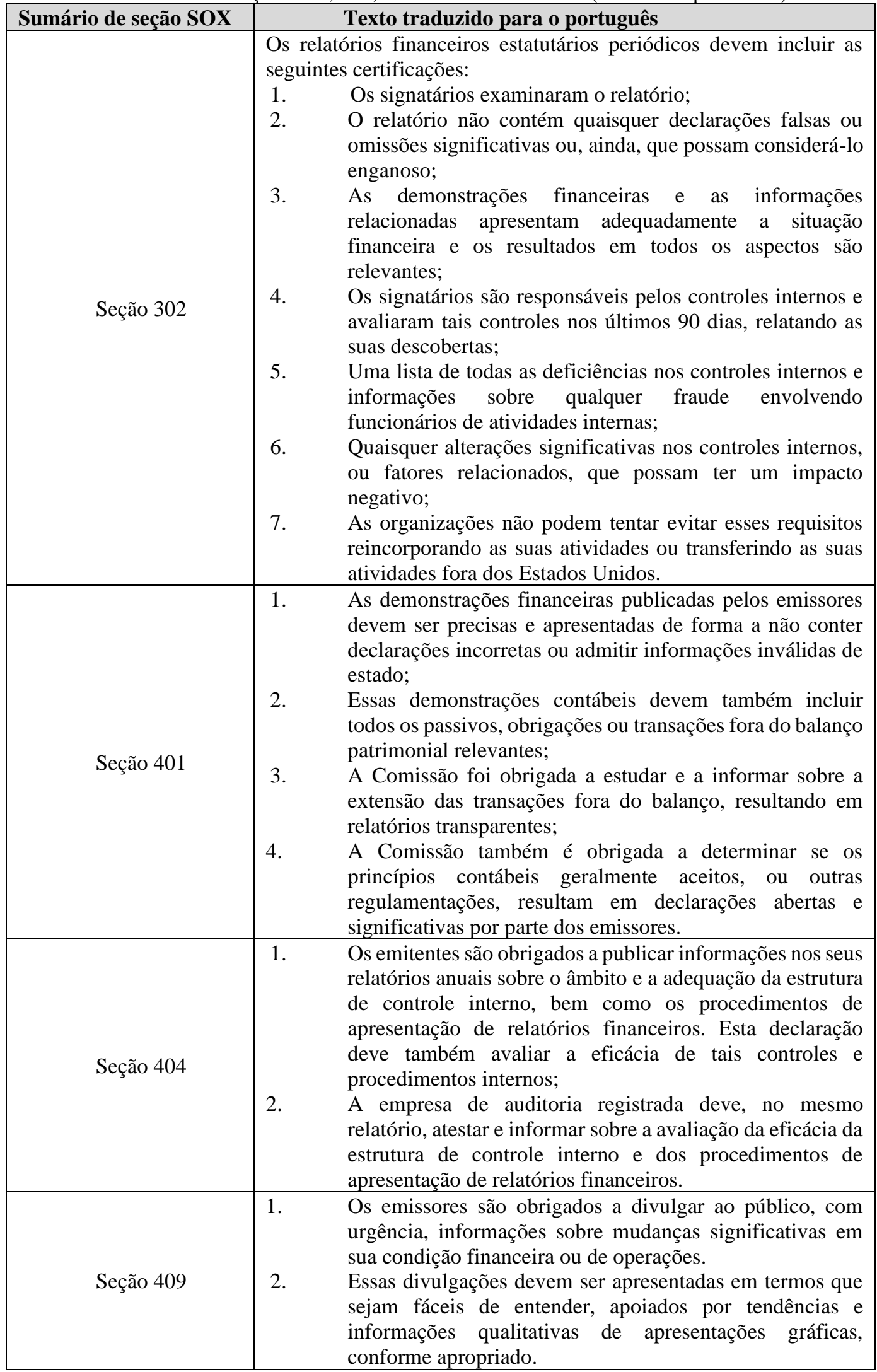

Fonte: http://www.soxlaw.com/introduction.htm (Acesso em: 10 dez. 2016). 
Tomando como base as considerações de Laurence Bardin (2004), nas quais indicam a possibilidade de análise de palavras-chave por meio de dois grupos: as palavras-plenas e as palavras-instrumentos. As palavras-plenas são as palavras compostas, por adjetivos, substantivos e verbos. Já as palavras-instrumentos são funcionais de ligação, como artigos, preposições, pronomes, dentre outros. Desta forma, a partir do sumário das seções da SOX do Quadro 2, construiu-se o Quadro 3 com as palavras-plenas levando-se então em conta a representatividade das palavras em cada seção.

Quadro 3: Palavras-plenas selecionas.

\begin{tabular}{|c|c|c|}
\hline Sumário de Seção SOX & Palavras-plenas selecionadas & Termos para pesquisa \\
\hline Seção 302 & $\begin{array}{l}\text { relatório financeiro/relatórios } \\
\text { financeiros } \\
\text { demonstração } \\
\text { financeira/demonstrações financeiras } \\
\text { signatário } \\
\text { omissão } \\
\text { deficiência } \\
\text { controle interno }\end{array}$ & $\begin{array}{l}\text { RELAT/FINANC } \\
\text { DEMON } \\
\text { SIGN } \\
\text { OMI } \\
\text { DEFIC } \\
\text { CONTR/INT }\end{array}$ \\
\hline Seção 401 & $\begin{array}{l}\text { declaração precisa } \\
\text { declaração incorreta } \\
\text { demonstração contábil } \\
\text { passivo } \\
\text { obrigação } \\
\text { balanço patrimonial } \\
\text { relatório transparente } \\
\text { princípio contábil }\end{array}$ & $\begin{array}{l}\text { DECL/PREC } \\
\text { INCORR/ERRA } \\
\text { CONTA } \\
\text { PASS } \\
\text { OBRIG } \\
\text { BALAN } \\
\text { TRANSP } \\
\text { PRINC } \\
\end{array}$ \\
\hline Seção 404 & $\begin{array}{l}\text { adequar / adequação } \\
\text { apresentação de relatório } \\
\text { auditoria }\end{array}$ & $\begin{array}{l}\text { ADEQ } \\
\text { APRES } \\
\text { AUDIT }\end{array}$ \\
\hline Seção 409 & $\begin{array}{l}\text { divulgar ou publicar (relatório } \\
\text { financeiro) } \\
\text { urgente /urgência } \\
\text { mudança } \\
\text { condição financeira } \\
\text { gráfico/gráfica } \\
\text { fácil/fáceis }\end{array}$ & $\begin{array}{l}\text { DIVUL/PUBL } \\
\text { URGEN/EMERG } \\
\text { MUDA/CAMB } \\
\text { CONDI/ESTAD } \\
\text { GRAF } \\
\text { FACIL }\end{array}$ \\
\hline
\end{tabular}

Fonte: O autor, 2019

Ainda sobre a metodologia aplicada, foram desprezados os termos pesquisados que trouxeram resultados com a mesma parte pesquisada, porém, adequando a outro termo, como, por exemplo, RELAT - "relatório" contabilizado, "relate" (verbo) desprezado. Foram computadas apenas uma vez as expressões encontradas por mais de uma vez, porém se referiam a um mesmo termo pesquisado, por exemplo: RELAT / FINANC - "relatório financeiro", contabilizado apenas uma vez. Foram também desprezados os termos encontrados que fugiam ao contexto da pesquisa, por exemplo: ADEQ - adequadamente todos os equipamentos de proteção individual. 
Após as análises das palavras-plenas, foi utilizada a técnica de análise temática, em que se estabeleceu categorias, previamente selecionadas, para analisar os documentos. Desta forma, para este estudo, as categorias foram as próprias propostas das seções 302, 401, 404 e 409 da SOX. Assim, a análise temática trouxe a proximidade de cada código de ética de forma qualitativa em relação à cada categoria.

Em relação às palavras-plenas selecionadas da seção 302, nota-se uma maior frequência para as que se seguem: (relatórios) financeiros, (demonstrações) financeiras, omissão $e$ controle interno. Os termos para signatário e deficiência pouco foram encontrados. Tal constatação pode ser entendida pela especificidade das palavras não encontradas, bem como pela generalidade ou pelo apelo das que foram encontradas, mesmo que no contexto investigado. Desta maneira, percebe-se que a maioria das palavras-plenas investigadas foi encontrada.

No tocante às palavras-plenas da seção 401, percebe-se a maior frequência para: (declaração) precisa, (demonstração) contábil, obrigação, (relatório) transparente e princípio contábil, ao passo que (declaração) incorreta, passivo e balanço patrimonial foram pouco encontradas. Tal como no parágrafo anterior, nota-se que as especificidades das palavras-plenas pouco foram encontradas. Desta forma, percebe-se que a maioria das palavras-plenas investigadas foram encontradas.

No que se refere às palavras-plenas da seção 404, percebe-se que as mais encontradas foram: apresentação/divulgação (de relatório) e auditoria, sendo a palavra adequar/adequação pouco encontrada. Em relação à palavra-plena referente à adequação, julgava-se que esta seria mais frequente nos códigos, uma vez que não apresenta tanta especificidade de lei. No entanto, poucas ocorrências foram verificadas, e a importância desse termo na Lei SOX toma grandes proporções. Ainda assim, percebe-se que a maioria das palavras-plenas investigadas foi encontrada.

Já em relação às palavras-plenas da seção 409, apenas a palavra-plena divulgar ou publicar (relatórios financeiros ou contábeis) foi amplamente encontrada. Paralelamente, urgente/urgência, mudança, condição financeira, gráfico/gráfica e fácil/fáceis não foram encontradas com tanta frequência. Poucos códigos, de maneira mais evidente, se comprometeram com o fator de temporalidade e de câmbio de estado que essa seção da SOX se propõe. No entanto, todos, de maneira evidente, preveem um local reservado para a divulgação de seus resultados.

Desta maneira, percebe-se que a maioria das seções da SOX investigadas teve a maior parte de suas palavras-plenas pesquisadas amplamente encontradas, o que corrobora para uma 
investigação mais geral, logo, o que os códigos de ética buscam convergir para os preceitos pilares da Lei SOX, representada, neste relatório, pelas seções 302, 401, 402 e 409.

\section{CONSIDERAÇÕES FINAIS}

Em um meio corporativo cada vez mais exigente de accountability e de fairness, nos sentidos de ampliação de responsividade e de senso de justiça, respectivamente, a Lei SarbanesOxley (SOX) vem regulando o mercado acionário nas empresas que negociam papéis na NYSE desde o início dos anos 2000. Para tais companhias, imersas neste contexto, a obrigatoriedade da adoção de um código de ética tornou-se incontornavelmente necessária. Assim, os códigos de ética adquiriram a importância de compliance, a partir da visão da SOX.

No entanto, num caminho contrário, mesmo que aparentemente baseado nos códigos de ética, o que se vê é a formação de um formalismo da ética dentro de uma visão de ética empresarial. Neste sentido, os códigos de ética funcionam como ferramenta de disclosure das empresas no que se refere ao esperado nas vertentes de comportamento, conduta e ética para a alta direção, os empregados, os fornecedores e os clientes.

Neste panorama, entendeu-se que a seção 406 da SOX vem para garantir o fluxo da Lei Sarbanes-Oxley para os códigos de ética. Desta maneira, a busca pela recíproca, ou seja, partindo-se do pressuposto de que, a partir de uma análise do código de ética, seja possível enxergar a Lei SOX, torna-se importante o viés ético no sentido de se evidenciar aspectos de coerência e de coesão do ponto de vista da ética empresarial - e se esses ocorrem apenas por mera formalidade de compliance.

Como cada empresa elabora o seu código de ética, torna-se pouco factível fazer uma generalização. Desta maneira e a fim de se buscar um entendimento mais profundo, mesmo que resumido a algumas empresas importantes do cenário econômico nacional, foram selecionadas as cinco empresas brasileiras com melhor desempenho na NYSE entre janeiro e julho de 2016. Estas cinco empresas tiveram os seus códigos de ética estudados no presente trabalho no intuito de se verificar se a recíproca ocorre - ou seja: se é possível perceber uma coerência e uma coesão da ética empresarial ao se enxergar a Lei SOX a partir de seus códigos de ética, bem como se estes aspectos ocorrem apenas por mera formalidade de compliance. Como a Lei SOX é extensa e com muitas seções, as seções tidas como "básicas" foram as norteadoras na pesquisa: seções 302, 401, 404 e 409.

Quanto à coerência, todos os códigos de ética apresentaram correspondências com todas as seções básicas da SOX, ainda que a maioria não tenha atendido plenamente aos itens das 
seções na sua totalidade. A coerência pôde ser verificada no seguinte aspecto: para os itens mais gerais das seções, foram encontradas correspondências, ao passo que para os com maior especificidade, não - o que seria natural, levando-se em conta um caráter mais generalista do código de ética. Já a aplicabilidade dos cinco códigos de ética sugeriu certo padrão, mesmo não o confirmando em números: as correspondências dos códigos de ética das cinco empresas convergiram para praticamente os mesmos itens das seções selecionadas da SOX. Importa referir que, para os outros itens, não houve correspondência.

Assim, em jeito de conclusão inicial, como cada seção teve correspondência, este trabalho pôde concluir que, de fato, há indícios suficientes para afirmar que há presença de coerência do ponto de vista de disclosure da ética empresarial - partindo dos códigos de ética das empresas selecionadas em direção às seções pesquisadas da Lei SOX.

Quanto à coesão, a maioria dos códigos de ética estudados apresentou falta de correspondência com pelos menos um item de cada seção selecionada da Lei SOX, exceto pela empresa CEMIG pois demonstrou correspondências temáticas em todos os itens verificados na presente pesquisa. Assim, em uma visão geral, houve lacunas entre os itens selecionados de cada seção investigada da Lei SOX, o que propõe uma desconexão entre os itens de cada seção. Desta forma, este relatório conclui que, para a maioria dos casos, não há indícios suficientes para se afirmar a presença de coesão do ponto de vista de disclosure da ética empresarial partindo dos códigos de ética das empresas selecionadas em direção às seções pesquisadas da Lei SOX.

Este artigo evidencia um aspecto importante: apesar de, na maioria dos casos estudados, não haver indícios suficientes para afirmar a coesão, entendeu-se que houve evidências para afirmar que, de fato, houve coerência e que essa se deu de uma forma padronizada em relação ao ponto de vista de disclosure da ética empresarial. Assim sendo, o trabalho abriu precedentes para que se propusesse às empresas, ao revisitarem os seus códigos de ética, a tentativa, de alguma forma, de preenchimento das lacunas acusadas pela falta de correspondência com os pilares da Lei SOX - sem perder a generalidade a que o código se propõe. Desta forma, garantirse-á uma maior proximidade em relação à coerência e à coesão no viés da ética empresarial entre os códigos de ética e os pilares da Lei SOX.

Finalmente, como os resultados apresentaram, em sua maioria, uma sugestiva padronização (e que as convergências apontaram para os itens mais gerais das seções estudadas), este relatório conclui que, na maioria dos códigos de ética estudados, houve uma significativa preocupação de cumprimento por formalidade, sob a perspectiva de coerência e de coesão em relação às seções estudadas da Lei SOX. Sugere-se, para trabalhos futuros, na 
vertente da ética empresarial, investigar a influência da segregação de funções empresariais na prática de accountability para alguma empresa brasileira que já negocia papéis na NYSE. Essa proposta permitiria enxergar mais a fundo como segregar funções contribui para uma ampliação de responsividade em uma empresa.

\section{Notas:}

${ }^{i}$ Campos (1990) foi uma das primeiras entre os/as pesquisadores/as brasileiros/as a relatar o termo e trazê-lo para debate no Brasil.

ii Entendo como consolidação da democracia, dentre outros fatores, a extinção da censura, o estabelecimento de eleições diretas para presidente da República, a diminuição da intervenção estatal na economia e eleições federais legítimas e a alternância de poder.

iii Apenas a título de complementação e também de contextualização, Sabrina Baracchini (2002) também explica que o termo accountability tornou-se parte de discursos políticos, apesar de não ser verificado com frequência na vida cotidiana do brasileiro. $\mathrm{O}$ autor ainda afirma que uma forma de inserir práticas de accountability no contexto brasileiro seria por meio da consolidação da prática cidadã, criando-se mecanismos de cobrança ou de responsabilização de agentes em ação estatal.

ivá se sabe que o código de ética é mencionado na seção 406 da Sarbanes-Oxley (2002), a qual prevê o dever de a empresa divulgar o código de ética, disponibilizando-o em meio público e, tão importante quanto: ser amplamente conhecido por conselheiros, diretores e funcionários. Desta forma, verifica-se que há um elo, tendo como ponto de partida a lei e como ponto de chegada o código de ética.

v Entendimento este que, partindo do pai da filosofia, Sócrates, em relação ao mandamento "conhece-te a ti mesmo" - e a sua morte pela liberdade de pensamento e pelo respeito das leis democráticas - adquire aqui fundamental importância.

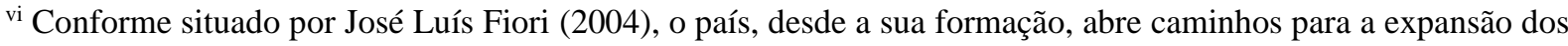
negócios e das grandes corporações que integraram o mercado nacional americano.

vii O que abriu espaço para ações duvidosas do ponto de vista ético e que convergiram, desta forma, para grandes escândalos corporativos nos Estados Unidos, como os da Enron e WorldCom, empresas norte-americanas envolvidas em fraudes de bilhões de dólares.

viii Nos Estados Unidos, há uma escola para a ética aplicada no âmbito empresarial: a Business Ethics. De acordo com Maria Kreitlon (2004), tal escola propõe um tratamento de cunho filosófico, normativo, centrado em valores e em julgamentos morais. A autora ainda coloca que essa escola tinha o protagonismo dos EUA justamente pelo fato de o país ser o centro do capitalismo no mundo e, somente mais tarde, passou a ser difundido pelo Brasil e pelo mundo. Apesar de as escolas éticas nos Estados Unidos serem comuns a partir do final dos anos 60, popularizando-se na década de 80 , tal escola ganhou força somente a depois de os escândalos corporativos das grandes empresas Enron e WorldCom terem vindo à tona.

ix $\operatorname{IBGC}(2015$, pg. 94)

${ }^{x}$ Entidade de iniciativa privada e sem fins lucrativos criada em 1985, nos Estados Unidos, para guiar a Comissão Nacional de Relatórios Financeiros Fraudulentos naquele país.

${ }^{x i}$ Vale mencionar que a COSO tem sido patrocinada e financiada por: American Accounting Association (AAA), American Institute of Certified Public Accountants (AICPA), Financial Executives International (FEI), Institute of Management Accountants (IMA) e The Institute of Internal Auditor (IIA) (COSO, 2013).

xii No Brasil, o órgão que exerce papel similar é a Comissão de Valores Mobiliários (CVM), normatizadora da Bolsa de Valores de São Paulo (BOVESPA).

xiii Revista Exame, 10 brasileiras que são destaque na Bolsa de Nova York, 13 de setembro de 2016. http://exame.abril.com.br/mercados/10-brasileiras-que-sao-destaque-na-bolsa-de-nova-york. Último acesso em 10 de dezembro de 2016. 


\section{REFERÊNCIAS}

BARACCHINI, S. A. A inovação presente na administração pública brasileira. Revista de Administração de Empresas, São Paulo, v. 42, n. 2, p. 1-6, 2002. Disponível em: https://dx.doi.org/10.1590/S0034-75902002000200010. Acesso em: 12 ago. 2019.

BARDIN, L. Análise de conteúdo. 3. ed. Lisboa, Portugal: Edições 70, 2004.

CAMPOS, A. M. Accountability: quando podemos traduzi-la para o português? Revista de Administração Pública, Rio de Janeiro, v. 24, n. 2, 30-50, 1990. Disponível em:

http://bibliotecadigital.fgv.br/ojs/index.php/rap/article/view/9049. Acesso em: 12 ago. 2019.

CENEVIVA, R. Accountability: novos fatos e novos argumentos - uma revisão da literatura recente. In: Encontro de Administração Pública e Governança, 2., 2006, São Paulo. Anais [...], São Paulo, ANPAD, 2006. Disponível em:

http://www.anpad.org.br/admin/pdf/ENAPG118.pdf. Acesso em: 12 ago. 2019

FARIAS, R. P.; DE LUCA, M. M. M.; MACHADO, M. V. V. A metodologia COSO como ferramenta de gerenciamento dos controles internos. Contabilidade, Gestão e Governança, Brasília, v. 12, n. 3, p. 55-71, 2009.

FIORI, J. L. O Poder Global dos Estados Unidos: formação, expansão e limites. Petrópolis: Editora Vozes, 2004.

GITMAN, L. J. Princípios de Administração Financeira. 12. ed. Pearson Prentice Hall, 2010.

GRAHAM, M. L. Business ethics: an analysis of a company's training program influence on employee behaviour and morale. 2009, Tese (Doutorado). Disponível na ProQuest Dissertations Publishing ( $\mathrm{N}^{\circ}$. 3355620).

INSTITUTO BRASILEIRO DE GOVERNANÇA CORPORATIVA. Código das melhores práticas de governança corporativa. 5. ed. São Paulo: IBGC, 2015. Disponível em: http://www.ibgc.org.br/userfiles/files/2014/files/CMPGPT.pdf. Acesso em: 12 ago. 2019.

KAIZELER, A. C.; FAUSTINO, H. C. Ética, globalização e ética da globalização: nº 1/2008. Lisboa: SOCIUS, 2008. (SOCIUS Working Papers). Disponível em:

http://hdl.handle.net/10400.5/1904. Acesso em: 12 ago. 2019.

KREITLON, M. P. A Ética nas Relações entre Empresas e Sociedade: fundamentos teóricos da responsabilidade social empresarial. In: Encontro da ANPAD, 28., 2004, São Paulo. Anais [...]. São Paulo: ANPAD, 2004. Disponível em: http://www.anpad.org.br/admin/pdf/enanpad2004-gsa2651.pdf. Acesso em: 12 ago. 2019.

MOREIRA, J. M. A ética empresarial no Brasil. São Paulo: Pioneira, 1999. 
O’DONNELL, Guilhermo. Accountability horizontal e novas poliarquias. Lua Nova: Revista de Cultura e Política, São Paulo, n. 44, p. 27-54, 1998.

OLIVEIRA, M. A.. Ética e sociabilidade. São Paulo: Editora Loyola, 1993

PAUL, S. Accountability in public services: exit, voice and control. World Development, Michigan, v. 20, n. 7, p. 1047-1060, 1992. Disponível em: https://gife.org.br/wp/media/2016/02/paul_1992.pdf. Acesso em: 12 ago. 2019.

PINHO, J. A. G.; SACRAMENTO, A. R. S. Accountability: já podemos traduzi-la para o português? RAP: Revista de Administração Pública, v. 43, n. 6, p. 1343-1368, 2009. Disponível em: http://bibliotecadigital.fgv.br/ojs/index.php/rap/article/view/6898/5471. Acesso em: 12 ago. 2019.

PONTES, C. S. A atuação da Justiça Eleitoral na fiscalização das contas dos candidatos e dos partidos políticos. Dissertação (Mestrado em Direito) - Pontifícia Universidade Católica do Rio de Janeiro, Rio de Janeiro, 2008. Disponível em: https://www.maxwell.vrac.pucrio.br/13478/13478_1.PDF. Acesso em: 12 ago. 2019.

REGINATTO, V. A. Análise de conteúdo do código de ética dos profissionais de Administração. Trabalho de conclusão de curso (Bacharel em Administração) -Universidade Federal do Rio Grande do Sul, Porto Alegre, 2012.

SILVA, R. C. F.; SEIBERT, R. M. Governança corporativa: história e tendências. Revista Interdisciplinar Científica Aplicada, Blumenau, v. 9, n. 3, p. 76-101, 2015.

SOUZA, M. M. et al. Evidenciação das exigências da Lei Sarbanes-Oxley nas empresas brasileiras que negociam ADRs nos Estados Unidos. RIC: Revista de Informação Contábil, Recife, v. 5, n. 3, p. 98-117, 2011.

U.S. SECURITIES AND EXCHANGE COMMISSION. Lei SARBANES-OXLEY, de 30 de julho de 2002. Disponível em: https://www.sec.gov/about/laws/soa2002.pdf.

VERGARA, S. C. Projetos e relatórios de pesquisa em administração. 14. ed. São Paulo: Atlas, 2013.

\section{EMPRESAS CONSULTADAS}

BANCO BRADESCO S.A. Disponível em: https://banco.bradesco/html/classic/index.shtm.

COMPANHIA ENERGÉTICA DE MINAS GERAIS - (CEMIG). Disponível em: http://www.cemig.com.br/pt-br/Paginas/default.aspx. Acesso em: 12 ago. 2019. 
COMMITTEE OF SPONSORING ORGANIZATIONS OF THE TREADWAY COMMISSION. ERM Gerenciamento de Riscos Corporativos: Estrutura Integrada. Disponível em http://www.iiabrasil.org.br/new/2013/downs/coso/COSO_ICIF_2013_Sumario_Executivo.pdf. Acesso em: 12 ago. 2019. Acesso em: 12 ago. 2019.

COMPANHIA DE SANEAMENTO BÁSICO DE SÃO PAULO. Disponível em http://site.sabesp.com.br/site/Default.aspx. Acesso em: 12 ago. 2019.

COMPANHIA SIDERÚRGICA NACIONAL. Disponível em: http://www.csn.com.br.

EXAME. Disponível em: http://exame.abril.com.br/mercados/10-brasileiras-que-saodestaque-na-bolsa-de-nova-york. Acesso em: 12 ago. 2019.

GOL Linhas Aéreas Inteligentes S. A. Disponível em: https://voegol.com.br/pt. 